\title{
Cinema e incorporações: reflexões e possibilidades educativas
}

Cinema and Embodiment: reflections and educational possibilities

\author{
Rodrigo Ferrari \\ Monica Fantin ii \\ Universidade Federal de Santa Catarina
}

\begin{abstract}
Resumo
Neste artigo apresentamos uma pesquisa sobre as possibilidades de ampliar a compreensão da relação entre cinema e educação a partir dos fenômenos e mecanismos da percepção e da cognição numa dimensão corporal, que estamos denominando de incorporações. O objetivo é especificar novas possibilidades e discutir novos limites teóricos e didáticos do ensino aprendizagem do cinema através das incorporações. Para isso, realizamos um estudo teórico e uma pesquisa aplicada articulando a didática e o cinema em diálogo com a mídia-educação. Entre as considerações, identificamos uma trilha fértil de novas possibilidades para ensinar e aprender cinema, a partir do cruzamento dos pontos de vista cognitivo, estético, cultural, social e político considerando o corpo como sujeito da percepção e da cognição.
\end{abstract}

Palavras chave: Educação; Cinema; Incorporações.

\section{Abstract}

In this paper we present a research on the possibilities of extending the understanding of the relation between the cinema and education through the perception and cognition phenomena in an corporeal dimension, which we denominate embodiments. The objective is to specify new possibilities and discuss new theoretical and didactic limits of teaching and learning cinema through embodiments. To do so, we developed a theoretical study and an applied research articulating the didactics and the cinema in a dialogue with the Media Education field. As part of our considerations, we identified an abundant track of new possibilities for teaching and learning cinema, through the intertwining of the cognitive, aesthetic, cultural, social and political points of view, considering the body as the subject of perception and cognition.

Keywords: Education; Cinema; Embodiments.

\section{Introdução}

A relação entre cinema e educação remonta ao surgimento do cinema, quando revistas especializadas publicavam análises e comentários sobre o cinema, e intelectuais, políticos, educadores e cineastas escreviam sobre os possibilidades deste "recurso" nas escolas.

Revista Digital do LAV - Santa Maria - vol. 10, n. 2, p. 17 - 38 - mai./ago. 2017 ISSN 1983 - 7348 http://dx.doi.org/10.5902/1983734828785 
Assim, em diversos contextos socioculturais é possível observar iniciativas que envolvem experiências como cine fórum, cinema na escola, eventos culturais e outras práticas informais ou institucionais que também repercutem em políticas públicas governamentais, estudos e pesquisa acadêmicas.

Nos últimos anos, as atividades de produção de audiovisual nas escolas têm despertado um interesse pedagógico que tem envolvido sobretudo leitura e análise de filmes com objetivo de motivar discussões e ilustrar conteúdos curriculares. O caráter de recurso ou ferramenta didática alterna-se com o caráter não intencional com uso de filmes no improviso em substituição de outras atividades. Além disso, o sentido de objeto de conhecimento e da intervenção educativa que o cinema pode viabilizar na perspectiva da mídia-educação, que envolve a mediação educativa de educar para, com e através do cinema pode ser entendida como fruição/apreciação, análise/interpretação e expressão/produção. As implicações político-pedagógicas de tais abordagens foram amplamente discutidas em diversos trabalhos (Rivoltella 1998, Bergala 2002, Franco 1997, Fantin, 2003, 2006, 2011, 2014).

Embora grande parte dos argumentos justifiquem o cinema na escola devido o seu caráter educativo e cultural, concordamos com Xavier (2008) quando diz que "cinema que educa é" aquele que (nos) faz pensar sobre o cinema em si e sobre as mais variadas experiências que ele coloca em foco. Acrescentamos que "cinema que educa" é também aquele emociona, diverte, transforma e faz sentir, pensar, vibrar.

Nesse sentido, as experiências com cinema na escola se configuram tanto na perspectiva de um trabalho com leitura fílmica e/ou produção de audiovisual que envolve ensinaraprender a ver cinema, a educar para o consumo, e a produzir audiovisual como na promoção de encontros de crianças, jovens e professores com experiências "biopsicosocioculturais" significativas que alguns filmes propiciam. Além disso, o cinema como dispositivo, arte, linguagem possibilita ampliar o capital cultural, interagir com a diversidade e "confrontar" com formas de subjetividades e alteridades através das narrativas cinematográficas construindo diferentes processos de significação.

No contexto das interrogações sobre as experiências éticas e estéticas que o cinema coloca em jogo na diversidade de práticas educativas e culturais que assegura, investigamos o ensino aprendizagem do cinema através das incorporações com o objetivo de especificar novas possibilidades e discutir novos limites teóricos e didáticos do cinema. Esta investigação é fundamentada, sobretudo, em teorias/autores como a fenomenologia de Merleau-Ponty; as ciências cognitivas de Humberto Maturana e Francisco Varela; a neurociência de Giacomo Rizzolatti e Vittorio Gallese. A metodologia envolveu estudos e diálogos teóricos, assim como experimentos de pesquisas aplicadas no âmbito da didática. As considerações sugerem que as incorporações abrem novas possibilidade e limites de

Revista Digital do LAV - Santa Maria - vol. 10, n. 2, p. 17 - 38 - mai./ago. 2017 ISSN 1983 - 7348 http://dx.doi.org/10.5902/1983734828785 
ensino-aprendizagem do cinema ao partir do entendimento de que o corpo, antes do cogito cartesiano, é sujeito também da percepção e cognição.

No recorte escolhido para esta reflexão, primeiramente situamos a relação entre estética e cinema. Na seqüência traçamos um breve panorama das teorias do cinema a fim de situar a abordagem da cognição e percepção incorporada. Por fim, apresentamos alguns elementos de uma proposta de formação para educar com/sobre cinema de acordo com a perspectiva apontada.

\section{Aproximações entre estética, cinema e suas teorias}

Pensar a relação estética e cinema ${ }^{1}$ implica entendê-la como parte de uma tradição de reflexão teórica sobre as artes em geral, dado que muitas teorias do cinema se referem à estética. Estética, do grego aisthesis, significa percepção, sensação. Para Baumgarten, um dos precursores do conceito, a estética se construiu como ciência relacionada ao âmbito do "sensitivo", que é mais amplo que o âmbito do "sensível" e que indica tanto sensação como percepção². Como disciplina autônoma, a estética surgiu no século XVIII, como o estudo da beleza artística e de temas relacionados com o sublime, o grotesco, o cômico, o prazeroso e junto com a lógica e a ética, a estética compõe a tríade de ciências normativas da Filosofia, que estabelecem as regras a respeito do verdadeiro, do bom e do belo, nos lembra Stam(2003). Na modernidade, a estética é vista como "reinvindicação da corporeidade e da sua peculiar força cognoscitiva e produtiva: percepção, imaginação, fantasia, sentimento, intuição, gosto, gênio, todos os modos de conhecer-produzir o mundo, conectado ao corpo, impensável sem o corpo" (DIODATO, 2012, p19). E o autor continua sua reflexão argumentando que na contemporaneidade, a estética pode ser interpretada a partir da experiência de localização e ampliação, da experiência do encontro com a obra de arte e reflexão sobre a experiência estética, e como experiência corpo-mundo e espaço-tempo da relação que a experiência estética envolve. Em tal entendimento, Diodato afirma que a experiência estética seria uma "experiência cognoscitiva-produtiva do mundo através do corpo" (2012, p.15). Assim, para o autor, "a experiência estética é estruturalmente relacional (...) e eminentemente corporal" (2015, p.19).

Desse modo, a percepção e a sensibilidade de cada um seria potencialmente dotada de aparatos simbólicos (literários, musicais, artísticos-visuais) visto que a abordagem estética envolve diversos níveis de conhecimento: "Não se trata de aprender, de ensinar e de compartilhar uma explicação do texto visual, literário ou musical, mas de "chegar ao

\footnotetext{
${ }^{1}$ Nesse texto nossa compreensão sobre o cinema também se estende ao âmbito mais amplo do audiovisual, resguardadas suas especificidades históricas, contextuais e conceituais.

2 Para Baumgarten, "a estética (ou a teoria da arte liberal, gnoseologia inferior, arte de pensar o belo, arte da analogia da razão) é a ciência do conhecimento sensitivo". (apud Diodato, 2012, p.16)
} 
nível estético da "compreensão" que literalmente quer dizer com-preender, prender dentro de si, não só na mente mas também nas vísceras, no coração", destaca Dallari, (2005, p.99), e para o autor, a experiência estética envolve a experiência de corpos e não apenas o exercício de conhecimento abstrato.

Entre tantas possibilidades de entender a relação entre cinema e estética, destacamos alguns aspectos no âmbito da neuroestética, a partir de trabalhos pioneiros de Freedberg (2011) e Zeki e Lamb, para quem "cada forma de arte visual obedece as leis do sistema visual", ou seja, "dos processos neurais que elaboram os dados da visão retínica em que cores, forma, movimento e profundidade, são gerenciados por áreas específicas do córtex visual", explica Pinotti, (2016, p.65). Freedberg e Gallese (2007) avançam as descobertas de Rizzolatti ao investigar os neurônios espelhos - neurônios do córtex pré-motor que se ativa seja ao realizar ações em primeira pessoa, seja no casos em que vê imagens e ações realizadas por outros. Assim, a relação entre imagens e as respostas somatopsíquicas do espectador revelaria invariantes biológicas e psicológicas que independem das diferenças de épocas e culturas (apud Pinotti, 2016, p.65). Com isso, não se pretende estabelecer uma base neural do que é ou não é arte, nem reduzir a experiência da arte a uma reação fisiológica, mas a intenção de descrever as implicações somatopsicológicas que são elucidadas pela fruição de imagens artísticas (e não só), esclarece Pinotti (idem, p.66). Perspectiva análoga também pode ser encontrada no $O$ olho da mente, do neurologista Oliver Sacks (2011), quando pergunta-se: "em que medida nós somos os autores, os criadores de nossas experiências? Até que ponto elas são predeterminadas pelo cérebro ou pelos sentidos que temos desde que nascemos, e em que medida, ao contrário, somos nós mesmos a plasmar o nosso cérebro através das experiências?"

Assim, enfatizamos as relações entre indivíduo e cinema a partir de uma perspectiva de interação entre corporeidade, consciência, cinema e suas experiências. A partir de tais relações, o individuo sente, apropria, identifica-se/define-se/transforma-se (?) com e através delas em sua sensibilidade, percepção e cognição entrelaçadas com os acontecimentos que o cinema promove.

Relacionado a tal perspectiva, no contexto da mídia-educação, o cinema pode ser entendido a partir das dimensões estéticas, cognitivas, sociais e psicológicas de forma inter-relacionada, destaca Fantin (2006 e 2011). A autora (2017) esclarece que em uma perspectiva ecológica da mídia-educação é possível pensar na dimensão estética da prática pedagógica e em todas experiências que a didática como montagem de objetos culturais coloca em jogo, que por sua vez que se constrói na pluralidade de sentidos de um trabalho com as multiliteracies, que tem no cinema um lugar de destaque.

Nesse quadro, o entendimento do cinema como arte, linguagem, dispositivo, objeto de conhecimento, meio de comunicação, instrumento e meio de expressão de pensamentos e

Revista Digital do LAV - Santa Maria - vol. 10, n. 2, p. 17 - 38 - mai./ago. 2017 ISSN 1983 - 7348 http://dx.doi.org/10.5902/1983734828785 
sentimentos também pode ser entendido em diálogo com as diversas interpretações a respeito das teorias do cinema. Vale destacar que a teoria do cinema envolve "um corpo de conceitos em permanente evolução, concebido para explicar o cinema em suas várias dimensões (estética, social, psicológica) para uma comunidade de estudiosos, críticos e espectadores interessados" (STAM, 2003, p.20). Nesta evolução, as teorias transformamse continuamente deixando seus rastros, e mesmo mudando suas ênfases, temas como "mimese, autoria, espectatorialidade - têm sido reiterados e reelaborados desde o princípio". Por vezes, "os teóricos abordam as mesmas questões, respondendo-as à luz de diferentes objetivos e em uma linguagem teórica distinta" , continua o autor (idem, p.23). Diversos estudos afirmam que as origens da "teoria do cinema" começa a ser construída em 1916 (Stam, 2003, Xavier, 1998), a partir do primeiro estudo do meio cinema, The photoplay: A psicological study, de, Hugo Münsterberger (1970), psicólogo e filósofo de Harvard. Sua abordagem psicológica orientava-se pela filosofia idealista que explicava a percepção e a cognição como processos mentais centrados no sujeito. Merleau-Ponty, em texto publicado originalmente em 1945, esclarece que

De um modo geral, a psicologia clássica transforma a percepção num autêntico decifrar intelectual dos dados sensíveis e numa espécie de princípio de ciência. Signos são-me dados e é necessário que extraia a sua significação; um texto me é apresentado e é necessário que eu o leia ou o interprete. Mesmo quando toma em conta a unidade do campo de percepção, a psicologia clássica permanece fiel à noção de sensação, que fornece o ponto de partida da análise; pelo fato de ter, sobretudo, concebido os dados visuais como um mosaico de sensações, ela tem necessidade de fundar a unidade do campo perceptivo numa operação intelectual (MERLEAUPONTY, 1983, p. 106).

A abordagem da percepção e cognição como operações intelectuais, ao lado da psicanálise e da linguística compõem importantes matrizes teóricas nas teorias do cinema, segundo Stam (2003). "A linguística e a psicanálise não foram escolhidas por razões arbitrárias de modismo, mas por serem consideradas duas ciências que lidavam diretamente com a significação" (STAM, 2003, p. 184).

A teorização psicanalítica buscava explicar o poder do cinema sobre os sentimentos humanos ao lado da capacidade persuasiva do dispositivo cinematográfico, destaca Stam (2003, p.185). O autor esclarece que diversos trabalhos promoviam o encontro entre cinema e psicanálise desde o surgimento do cinema, mas para Xavier (1983), foi no início

Revista Digital do LAV - Santa Maria - vol. 10, n. 2, p. 17 - 38 - mai./ago. 2017 ISSN 1983 - 7348 http://dx.doi.org/10.5902/1983734828785 
dos anos 1970 que Louis Baudry abordou os dois níveis de identificação dos espectadores com os filmes: o primeiro é do sujeito com o visível dos filmes, e o segundo com a ordem do visível que posiciona o sujeito nas histórias dos filmes. Para Baudry (1970), o sujeitoespectador é a origem do sentido dos filmes, a consciência da objetividade do que é visto. Como em Münsterberger, o conceito de sujeito utilizado por Baudry é o sujeito transcendental do idealismo kantiano e husserliano, condição de possibilidade da percepção e da cognição (XAVIER, 1983).

O ponto de vista do sujeito-espectador é determinado pela câmera, que segundo Baudry(1970), no cinema tradicional coloca o sujeito-espectador num ponto de vista central da história, a mesma perspectiva da arte renascentista e do romance no início do iluminismo. Portanto, o cinema reproduziria o aparelho psíquico dos sujeitos e, segundo o autor, seria este o poderoso mecanismo responsável pelo envolvimento dos espectadores na recepção cinematográfica. Nesse sentido a montagem cinematográfica tradicional, centrada na continuidade dos planos e no trabalho de ocultamento de todo processo de produção cinematográfico são técnicas essenciais para que os espectadores se envolvam com os filmes. Um erro de continuidade ou de projeção interromperia o funcionamento do aparelho psíquico artificial do cinema que reproduz o aparelho psíquico do espectador e isso o afastaria dos filmes.

Nessa mesma direção, Metz (1977) explica que as identificações dos espectadores com os filmes ocorrem através das técnicas de ocultar os vestígios da produção cinematográfica, e assim o espectador se torna o próprio enunciador da história que vê. Nesse caso, a câmera é comparada com os olhos do sujeito, que no momento da recepção cinematográfica se torna um tipo de consciência sem corpo que vê e não é vista. Para o autor, a recepção cinematográfica seria destinada à "espectadores-deuses", onipresentes e invisíveis no contexto da história,

(...) que absorvem tudo pelos olhos e, nada pelo corpo: a instituição do cinema prescreve um espectador imóvel e silencioso, uma espectador alheado, em constante estado de submotricidade e superpercepção, um espectador alienado e feliz, acrobaticamente pendurado a si mesmo pelo fio invisível da visão, um espectador que não se recobra como sujeito senão no derradeiro instante, através de uma identificação paradoxal com a sua própria pessoa, extenuada no puro olhar (METZ, 1977, p. 409).

Nas décadas de 1980 e 1990, Carrol e Bordwell pesquisam o cinema a partir das ciências cognitivas. Para Bordwell (1989), as ciências cognitivas explicariam as atividades mentais

Revista Digital do LAV - Santa Maria - vol. 10, n. 2, p. 17 - 38 - mai./ago. 2017 ISSN 1983 - 7348 http://dx.doi.org/10.5902/1983734828785 
dos espectadores e como as representações dos filmes são criadas. Tais noções seriam explicadas como um complexo mecanismo de recepção e processamento de informações captadas do meio externo pelo sistema nervoso por meio de dois processos, um relacionado com informações simples e outro com informações mais complexas. 0 primeiro, chamado de bottom-up, opera no nível de "reações mais automáticas" do tipo "pegou fogo na casa = corra" e o segundo, top-down opera num processo reflexivo que envolve soluções de problemas e juízos abstratos, "pegou fogo na casa, mas meu cachorro está preso num quarto, como posso salvá-lo?".

Entre os fragmentos desta breve síntese, observamos que a recepção cinematográfica nas dimensões psicológicas, psicanalíticas e das ciências cognitivas, tem sido historicamente teorizada a partir do pressuposto de que a percepção e a cognição são fenômenos mentais, que envolvem a "consciência de". Em tal entendimento, podemos supor que o corpo e a corporeidade participam da percepção e da cognição como instrumentos secundários [e porque não descartáveis, afinal, se somos uma mente que habita uma corpo poderíamos habitar outros corpos, até um artificial]. E tal ideia de percepção e cognição também pode ser vista em filmes como Matrix (1999), RoboCop (2014) entre outros.

Na teorização linguística, o cinema é entendido como linguagem. Balázs, na década de 1920, foi um dos primeiros teóricos a defender a ideia de que o cinema era uma linguagem com uma gramática própria, sobretudo, a partir dos usos de close-up e da montagem, esclarece Xavier (1983). Considerando o uso da câmera como extensão da consciência dos espectadores, Balázs propõe que o cinema é a primeira arte que rompe a distância entre a obra e os sujeitos.

No cinema a câmera carrega o espectador para dentro mesmo do filme. Vemos tudo como se fosse do interior, e estamos rodeados pelos personagens. Estes não precisam nos contar o que sentem, uma vez que vemos o que eles veem e da forma em que veem. Embora nos encontremos sentados nas poltronas pelas quais pagamos, não é de lá que vemos Romeu e Julieta. Nós olhamos para cima, para o balcão de Julieta com os olhos de Romeu e, para baixo, para Romeu, com os olhos de Julieta. Nosso olho e com ele nossa consciência, identifica-se com os personagens no filme; olhamos para o mundo com os olhos deles e, por isso, não temos nenhum ângulo de visão próprio. Andamos pelo meio das multidões, galopamos, voamos ou caímos com o herói, se um personagem olha o outro nos olhos ele olha da tela para nós.

Revista Digital do LAV - Santa Maria - vol. 10, n. 2, p. 17 - 38 - mai./ago. 2017 ISSN 1983 - 7348 http://dx.doi.org/10.5902/1983734828785 
Nossos olhos estão na câmera e tornam- se idênticos aos olhares dos personagens. Os personagens veem com nossos olhos. É neste fato que consiste o ato psicológico da "identificação" (BALÁZS apud XAVIER, 1983, p. 85).

Nessa mesma época, Dziga Vertov e Sergei Eisenstein também enfatizaram aspectos teóricos do cinema como linguagem. Vertov, mais cineasta do que teórico, propunha experimentos de cine-olho, cine-verdade, como "possibilidade de tornar visível o invisível, de iluminar a escuridão, de desmascarar o que está mascarado, de transformar o que é encenado em não encenado, de fazer da mentira verdade" (VERTOV apud XAVIER 1983, p. 262). A obra O Homem com uma Câmera, de Vertov (1929), é diferente de tudo que estava sendo produzido em seu tempo e do que foi produzido até a contemporaneidade, com exceção do cinema etnográfico, campo em que o trabalho do cineasta é amplamente conhecido e referenciado.

Por sua vez, em 1926 Pudovkin sistematizou a respeito da montagem estrutural considerando a "lógica" de nossas percepções cotidianas. E Eisenstein (2002), além de seus filmes, ampliou tal proposta de montagem com um intenso investimento teórico no âmbito da montagem cinematográfica apresentando um método de cinco técnicas nessa mesma década.

Foram nos anos 1960 e 1970 que o cinema como linguagem foi teorizado mais intensamente a partir da Semiótica, que estuda a linguagem como sistema de signos, significados e significantes. O objetivo desta abordagem era definir a especificidade do cinema como linguagem, e Metz (1972) foi o principal teórico desta reflexão ao propor oito sintagmas da linguagem cinematográfica. Para ele, a linguagem cinematográfica é uma forma artística de expressão e comunicação e não um sistema, por exemplo, como a língua portuguesa, que se organiza de maneira paradigmática e sintagmática ${ }^{3}$. Entretanto, apesar das diferenças semióticas, o filme continua sendo explicado, na maioria das vezes, como um texto a ser "lido", analisado e interpretado pelos espectadores a partir das relações entre produção e recepção de significados.

Nas décadas de 1980 e 1990, a orientação semiótica foi ampliada pelas contribuições da semio-pragmática (Casetti, 2004), uma abordagem centrada nos mecanismos de produção simbólica cinematográfica e como um filme é entendido pelos espectadores no contexto de sua recepção. Desse modo, a recepção cinematográfica é explicada a partir de uma perspectiva sociocultural, ou seja, o espectador deixa de ser "receptor passivo" e

\footnotetext{
${ }^{3}$ Stam (2003) explica tal entendimento comparando os planos cinematográficos e as palavras. Os planos são infinitos e produzidos pelos cineastas, as palavras são finitas e preexistentes; um plano não se equivale a apenas um sinal ou significado; a palavra "cachorro" não é equivalente ao plano de um cachorro, que mostra um cachorro de cor, raça, tamanho, etc. específicos.
}

Revista Digital do LAV - Santa Maria - vol. 10, n. 2, p. 17 - 38 - mai./ago. 2017 ISSN 1983 - 7348 http://dx.doi.org/10.5902/1983734828785 
passa a ser entendido também como criador de significados que negocia suas formas de participação e posicionamento de acordo com suas diferenças e especificidades socioculturais. ${ }^{4}$

Nos últimos vinte anos, outras abordagens foram surgindo e de alguma forma criticam alguns limites teóricos da psicanálise e da semiótica como fundamentos da "Grande Teoria do Cinema". Assim, a teorização cinematográfica vai tornando-se mais diversa e plural, sobretudo com referências pós-estruturalistas e com os novos meios.

Nesse sentido, destacamos "o impacto de Deleuze", como diz Stam, que ao questionar "a grande teoria" em seus trabalhos Imagem-Movimento e Imagem-Tempo, estabelece outros conceitos para entender o cinema e suas relações com o tempo, espaço, memória. Deleuze percebe o cinema como "instrumento filosófico, um gerador de conceitos e um produtor de textos que traduz o pensamento em termos audiovisuais (...)"(2003, p.284). Nas relações entre cinema, corpo, cérebro, pensamento, "pensar é aprender o que pode um corpo não-pensante, sua capacidade, suas atitudes ou posturas. É pelo corpo (e não mais por intermédio do corpo) que o cinema se une com o espírito, com o pensamento", enfatiza Deleuze $(2005$, p.227) 5 .

Diante deste breve contexto histórico e conceitual do cinema, suas práticas e teorizações, podemos entender que somos corporeidades no mundo, cada qual com sua história, experiências e relações simbólicas, como diz Merleau-Ponty (2003). Antes de ser signo, as palavras pronunciadas são sons produzidos e ouvidos por corporeidades, gestos, ações, comportamentos. Incorporamos, antes de interpretar a palavra. Para Maturana e Varela (1995) a linguagem antes de paradigmática e sintagmática é uma coordenação de ações recursivas e recorrentes em que os organismos se automodelam durante suas derivas ontogênicas.

A percepção e a cognição incorporadas fornecem outro modelo explicativo da recepção cinematográfica. Ao pesquisar os circuitos de neurônios espelhos, Gallese e Goldman (1998) esclarecem que entendemos os objetos a partir de simulações de ações intencionais relacionadas aos objetos e na observação de comportamentos, sensações e emoções. O fenômeno de incorporação pode ser fundamentado por Merleau-Ponty (2003)

\footnotetext{
${ }^{4}$ Por exemplo, um cidadão iraquiano é um tipo de espectador de American Sniper (2014) totalmente distinto de um cidadão estadunidense. Da mesma forma é preciso considerar que Clint Eastwood dirigiu este filme para espectadores "ocidentais".

${ }^{5}$ Posteriormente, Deleuze afirma que as sensações, percepções, representações e [re]identificações do cinema e não só, levam a indeterminações e experimentações das quais podem surgir novas conexões. Ao unir a sensação e a cognição, agora recolocadas pela nova potência das máquinas que articulam informação e interação visando um sentido comum, surgiria um "novo inimigo do pensamento", a estupidez comunicacional, que Deleuze chamou de controle, esclarece Rajchman (2007, p.16): "estamos no início de algo novo", escreveu Deleuze em 1990 , e seria necessário identificar essas novas forças, as da biotecnologia e as digitais e seus vastos processos econômicos e sociais que são inseparáveis, pois delas poderia surgir um novo devir-arte que nos livraria daquela estupidez e dos nossos automatismos informáticos.
}

Revista Digital do LAV - Santa Maria - vol. 10, n. 2, p. 17 - 38 - mai./ago. 2017 ISSN 1983 - 7348 http://dx.doi.org/10.5902/1983734828785 
na filosofia, Maturana e Varela (1995) na biologia, Varela, Thompson e Rosch (1993) nas ciências cognitivas, e Rizzolatti, Fogassi e Gallese (2001) na neurociência. Assim, a partir dos circuitos de neurônios espelhos e das simulações incorporadas, ao invés de entendermos os filmes via processamento de informações, a recepção cinematográfica ocorre primeiro via incorporações. Rizzolatti, Fogassi e Gallese (2001) mostram os mecanismos neurológicos que possibilitam a percepção e a cognição incorporadas como um tipo de entendimento corporal pré-linguístico e pré-reflexivo.

Ao estudar o poder da imagem, sua força de atração sua capacidade de replicar e simular formas de experiência que incidem no movimento, o neurocientista Vittorio Gallese e o teórico do cinema Michele Guerra encontram no cinema o cruzamento dos pontos de vista estético, cultural, social e político. Ao perguntar pelo tipo de relação intersubjetiva entre os espectadores e os mundos possíveis da ficção que o cinema representa no imaginário coletivo, Gallese e Guerra (2015) percorrem a origem da intersubjetividade - tema amplamente tratado pela teoria, pela crítica e pela filosofia do cinema de modo a revitalizar e inovar tais questões à luz das neurociências cognitivas e da neuroestética. Nesta perspectiva, os circuitos cerebrais estão extremamente ligados à corporeidade, e nossa corporeidade não é reduzível a um objeto físico mas se realiza na esfera da experiência, como um corpo que age, sente, conhece e constrói experiência a partir de nossas relações com o mundo. Corporeidade que desenvolve um papel decisivo nas práticas de simulação, de ação e de sensação presente em nossa vida cotidiana, nas experiências estéticas e mediadas e particularmente no cinema.

Deste modo, diante da clássica pergunta "o que é o cinema", Gallese e Guerra (2015, p.14) respondem com outras perguntas que podem nos ajudar a entender outros âmbitos da relação cinema e educação:

"O que significa 'ver' um filme? Até que ponto e em que medida a irrealidade percebida da fiç̧ão cinematográfica se afasta da modalidade com que nos reportamos à realidade cotidiana em que estamos imersos? Por que a ficção narrativa do cinema frequentemente nos atinge e emociona mais que a vida real? Em que medida a nossa identidade, história pessoal e a contingente condição cultural de espectadores condicionam a fruição do filme? O quanto é importante considerar o nível de co-envolvimento empático e corpóreo para compreender como funciona a tecnologia do cinema? Qual é o melhor método para estudar o co-envolvimento com as imagens e sons do filme e a consequente imersão na ficção narrativa cinematográfica?" 
Perguntas que certamente contribuem para enriquecer e renovar nossa compreensão sobre o cinema e suas relações. Afinal, nos estudos sobre cinema, vimos que desde os anos vinte, artistas e teóricos outros estudaram o "impacto" dos meios óticos e acústicos de diferentes meios na história das percepções. A relação entre aparelhos técnicos e as formas de experiência sensível, como escreveu Benjamin (1996), se desenvolveu no interior de um "meio de percepção" em que as teorias das mídias, da história da arte e do cinema construíam os nexos entre estilos artísticos, história da tecnologia e história da experiência sensível e corpórea, como lembram Pinotti e Somaini (2016).

Num cenário multimidiático em contínua transformação, é cada vez mais necessário elaborar conceitos e instrumentos que nos ajudem a compreender a dimensão cultural das imagens e do olhar que é técnica, social e historicamente construída e que possui dimensões éticas, estéticas e biopsicosocioculturais. Desse modo, novas possibilidades e limites ainda poucos explorados se abrem para futuras teorizações do cinema e também da educação com e sobre o cinema. No recorte desse texto trazemos alguns olhares a esse respeito, inspirados em aspectos da pesquisa de Ferrari (2015).

\section{Corporeidade e incorporações: a percepção e cognição incorporadas}

Junto com o desenvolvimento das práticas e teorias do cinema, é possível perceber que as abordagens de ensino-aprendizagem no âmbito do cinema e educação foram construídas, sobretudo, a partir de fundamentos filosóficos e científicos que interpretam e explicam a percepção e a cognição como fenômenos mentais ${ }^{6}$. O corpo, nessa abordagem, é apenas um instrumento controlado pela mente, entidade abstrata responsável pela percepção e cognição. Não por acaso, Ferrari (2015) fundamenta-se em Merleau-Ponty (2006), para quem a corporeidade é a condição de possibilidade da percepção e da cognição7.

Esta abordagem, também se alinha com pesquisas e práticas contemporâneas nos campos da educação e didática, em que o corpo e a corporeidade vêm sendo colocados no centro de algumas propostas de ensino-aprendizagens, destaca Rivoltella (2012):

Nosso corpo não desenvolve apenas uma função de mediação sensorial ou apenas executa o que o cérebro e o ambiente externo demandam, mas constitui o dispositivo principal através do qual,

\footnotetext{
${ }^{6} \mathrm{Na}$ teoria do cinema isto pode ser observado em Stam (2003), no campo da educação em Rivoltella (2012).

7 Do ponto de vista da filosofia, para Edmund Husserl, o corpo e a ação constituem elementos pré-reflexivos da percepção, e posteriormente Maurice Merleau-Ponty argumenta sobre o que é incorporar no sentido cognitivo e perceptivo. Os biólogos Maturana e Francisco Varela por sua vez, explicam como as incorporações ocorrem a partir da noções de Autopoiesis e acoplamento estrutural. E mais recentemente, no âmbito neurológico Giacomo Rizzolatti seguiu a mesma trilha e inspirou experimentos de neurocientista Vittorio Gallese e o sentido cognitivo e perceptivo das incorporações. Neste artigo, o fenômeno das incorporações foi construído como fragmentos a partir da perspectiva científica e filosófica, com o objetivo de tecer de maneira rigorosa suas devidas conexões teóricas.
}

Revista Digital do LAV - Santa Maria - vol. 10, n. 2, p. 17 - 38 - mai./ago. 2017 ISSN 1983 - 7348 http://dx.doi.org/10.5902/1983734828785 
realizando experiências, desenvolvemos a aprendizagem e produzimos conhecimento. Isto é um grande avanço, sobretudo porque toda nossa tradição didática foi construída na direção oposta (RIVOLTELLA, 2012, p. 109).

O autor acrescenta que do ponto de vista neurológico, a percepção e a cognição são explicadas tradicionalmente como mecanismos anatômicos-fisiológicos de captação e processamento de informações. Nesse caso, a percepção do visível, por exemplo, é uma informação captada por nossos nervos óticos, que em seguida é levada para nossos córtex onde é processada. O conhecimento do visível seria a informação processada e o corpo apenas um instrumento da percepção e do conhecimento, porque para que a informação seja processada é preciso que haja um programa que execute o processamento da informação. No campo das ciências cognitivas, esta abordagem é conhecida como "modelo computacional da mente" (MATURANA e VARELA, 1995).

Além das pesquisas de Merleau-Ponty (2006) e de Maturana e Varela (1995), descobertas neurocientíficas publicadas na década de 1980 (RIZZOLATTI; FADIGA; GALLESE; FOGASSI, 1996) demonstraram evidências positivas de que há um mecanismo perceptivo e cognitivo anterior à computação mental. Durante a realização de experimentos de monitoração da atividade elétrica do córtex de macacos, estes neurocientistas italianos identificaram um mesmo padrão elétrico quando os macacos executavam uma ação motora simples e quando os animais apenas observavam a mesma ação sendo executada por outro macaco ou outro homem. Recentes pesquisas realizadas com a leitura de imagens do funcionamento do córtex humano através de ressonâncias magnéticas demonstram que os mecanismos de simulações neurológicas também estão presentes e funcionam da mesma maneira nos humanos (RIZZOLATTI; FADIGA; GALLESE; FOGASSI, 1996).

O sistema neurológico de espelhamento demonstra que ao observarmos uma ação, antes de processarmos a informação visual que "recebemos" do meio, percebemos e conhecemos a ação executada pelo outro através de simulações neurológicas em nossos córtex das ações que observamos. Isto é totalmente distinto do modelo de percepção e cognição como processamento de informação porque é independente do conceito de mente e suas variações. Além disso, a estrutura anatômica e os mecanismos do circuito neurônios espelhos explicam como incorporamos as ações que observamos. Nesse sentido, os neurônios espelhos e os mecanismos de simulações sensório-motoras demonstram um dos processos fisiológicos da percepção e da cognição incorporadas.

De acordo com Freedberg e Gallese (2007), o mesmo ocorre nas observações de sensações e emoções. Quando observamos a expressão de uma pessoa após provar uma

Revista Digital do LAV - Santa Maria - vol. 10, n. 2, p. 17 - 38 - mai./ago. 2017 ISSN 1983 - 7348 http://dx.doi.org/10.5902/1983734828785 
comida azeda, entendemos que a comida é azeda porque simulamos neurologicamente a expressão da pessoa que observamos, ou seja, seu comportamento. Os neurônios espelhos e os mecanismos de simulações sensório-motoras têm duas implicações significativas no âmbito do ensino-aprendizagem do cinema: 1) se incorporamos o que vemos, a experiência estética, antes de ser um juízo estético que depende da mente, deve ser considerada como uma experiência de incorporação sensório-motora; 2) as incorporações sensório-motoras ocorrem exatamente da mesma forma que quando vemos o corpo do outro diante de nós e quando vemos uma escultura, uma pintura ou uma fotografia.

As simulações sensório-motoras são mecanismos naturais presentes em nossa espécie, destacam Rizzolatti; Fadiga; Gallese; Fogassi (1996), porém, as experiências perceptivas e cognitivas são sempre particulares e dependentes da ontogenia de cada indivíduo. Segundo Gallese e Guerra (2012), o mesmo se aplica na observação das imagens em movimento do cinema, e sugerem que

o movimento, o espaço, objetos e ações são elementos cruciais a serem estudados no sentido de observar os filmes como espaços de interações e intersubjetividades. Propomos que estes elementos estão ligados com as funções das Simulações Incorporadas - SI (GALLESE, GUERRA, 2012,p. 206).

Há milhares de anos o mundo e as coisas são objetos percebidos e conhecidos pela mente. Ver, analisar, interpretar um filme, assim como se emocionar, sentir prazer ao assistir ou então produzir um filme seriam processos exclusivamente mentais, ou seja, seria um produto do sujeito cartesiano, que percebe e conhece os objetos pela mente. $\mathrm{Na}$ filosofia moderna, sujeito e objeto são categorias constitutivamente separadas, diz Merleau-Ponty (2003). Segundo ele, esta clivagem entre sujeito e objeto é artificial e posterior à evidência de que percebemos e conhecemos o mundo através de nossas corporeidades entrelaçadas no mundo. Aliás, o termo entrelaçamento é central para situar as reflexões merleau-pontyanas. Entender que as corporeidades são entrelaçadas no mundo significa reconhecer que há pelo menos um ponto de cruzamento entre as corporeidades e o mundo, um quiasma, tornando estes dois "objetos", separados e distintos, inseparáveis e indistintos.

A separação entre sujeito e objeto deve ser suspensa como um produto da reflexão ${ }^{8}$ e até mesmo da lógica, e o que permanece é um fenômeno que se mostra através da

\footnotetext{
8 Diante da polissemia do termo reflexão, neste texto entendemos como um fenômeno associado à consciência, à mente, ao pensamento, à razão, à linguagem simbólica, que também é tematizado em seu avesso, que é a préreflexão, fenômeno associado às incorporações.
}

Revista Digital do LAV - Santa Maria - vol. 10, n. 2, p. 17 - 38 - mai./ago. 2017 ISSN 1983 - 7348 http://dx.doi.org/10.5902/1983734828785 
impossibilidade de separar as corporeidades do mundo vivido, diz Merleau-Ponty (2003). $\mathrm{Na}$ dimensão reflexiva, a separação entre o sujeito e objeto continua sendo respeitada e coerente, porém há uma dimensão pré-reflexiva que também deve ser considerada, destaca o autor. Na introdução do livro de Merleau-Ponty (2004b), Thomas Baldwin explica o projeto merleau-pontyano:

O tema central da filosofia de Merleau-Ponty, desde a Estrutura do Comportamento até O Visível e Invisível é precisamente a forma como a corporeidade se integra na filosofia kantiana, no sentido de que não apenas "consciências", mas corporeidades que "se entrelaçam e constituem o mundo". O autor pontou isto na Fenomenologia da Percepção da seguinte forma: "com isso reconstruímos o ponto de contato entre a corporeidade e o mundo, podemos redescobrir nós mesmos, percebendo como percebemos com nossas corporeidades, que é um self natural e sujeito da percepção". Sua reinvindicação central é que nossas incorporações trazem à tona nossas experiências perceptivas uma estrutura a priori que se apresenta para nós como experiência consciente do mundo das coisas no espaço e no tempo naturalmente independente de nós. É a nossa intencionalidade corporal que possibilita os significados de nossas experiências assegurando que seus conteúdos, as coisas apresentadas em nossas experiências estão cercadas de referencias do passado e futuro, a outros lugares e coisas, as possibilidades e situações humanas (apud MERLEAUPONTY, 2004, p. 10).

Desse modo, não vemos apenas com os olhos da mente, como entendia Descartes (2004) e sugerem os racionalistas. Vemos, percebemos e conhecemos através das corporeidades antes de realizar qualquer operação mental de análise e interpretação. Por exemplo, percebemos e conhecemos o chão que pisamos como uma referência espacial constitutiva por nossos mundos vividos. Neste sentido, a perspectiva dos empiristas, que pressupõe a existência de uma objetividade independente das corporeidades também é limitada, pois de acordo com o entendimento de Merleau-Ponty, não há verdade empírica independente das corporeidades entrelaçadas ao mundo.

Ao ampliar os horizontes da revisão filosófica de Merleau-Ponty para o campo das ciências cognitivas, Varela, Thompson e Rosch (1993) contribuíram com o entendimento dos fenômenos da percepção e cognição da psicologia cognitiva contemporânea. Eles 
demonstram, por exemplo, que a nossa percepção das cores depende tanto de aspectos fisiológicos como culturais, e que o visível não é algo independente do vidente.

(...) as cores não são categorias que pertencem a um mundo objetivo independente de nossas capacidades perceptivas e cognitivas. As categorias vermelho, verde, amarelo, azul, roxo, laranja, assim como luz/quente, escuro/frio, amarelo-com-verde, etc., dependem de nossas experiências, consensos e incorporações: dependem da história de nossos acoplamentos estruturais biológicos e culturais. (VARELA; THOMPSON; ROSCH, p. 171, 1993). ${ }^{9}$

Os trabalhos de Merleau-Ponty (2003); Varela, Thompson e Rosch (1993) possibilitam profundas reflexões e entendimentos sobre o fenômeno da percepção e da cognição como incorporações e fazem parte dos primeiros esforços de construção teórica sobre os fenômenos de percepção e cognição incorporadas ou simplesmente incorporações. No desenvolvimento das pesquisas sobre os neurônios espelhos $e$ as simulações incorporadas, Gallese cita literalmente a profundidade e relevância da fenomenologia e indiretamente de Varela, Thompson e Rosch (1993) argumentando que "devemos fenomenologizar as ciências cognitivas ao invés de naturalizar a fenomenologia" (2005, p. 294).

\section{Uma experiência de educação para e com o cinema através da percepção e cognição incorporadas}

A partir do caminho teórico e pragmático percorrido por Ferrari (2015), identificamos alguns eixos para repensar o ensino-aprendizagem do cinema através da percepção e cognição incorporadas na formação de professores que atuam no campo da educação com e sobre o cinema. Embora estes eixos não configurem intencionalmente uma proposta fechada do tipo "receita" de formação, pois esta deve ser apropriada e operacionalizada de forma contextualizada, talvez possam indicar possíveis pistas para fazer parte da formação. Aliado a isso, ressaltamos a necessidade de mais reflexões teóricas e experiências didáticas a partir das incorporações cinematográficas, um campo ainda pouco

\footnotetext{
9 A expressão acoplamento estrutural é o ponto de partida dos autores para explicar como percebemos e conhecemos, uma variação biológica que se aproxima do conceito merleau-pontyano de entrelaçamento. Assim como o ser-no-mundo é um fundamento ontológico, o acoplamento estrutural é uma explicação filogenética e ontogênica de que somos organizações autopoiéticas acopladas estruturalmente ao meio. Para Varela, Thompson e Rosch (1993), a percepção e a cognição emergem no acoplamento estrutural dos organismos que simultaneamente moldam e são moldados pelo meio. Isto significa que as estruturas dos organismos se modificam e modificam a estrutura do meio simultaneamente através do acoplamento estrutural. A estrutura de um organismo é sua unidade corporal, por isso, as modificações que ocorrem nos organismos durante o acoplamento estrutural são nomeadas por Varela, Thompson e Rosch (1993) de incorporações.
} 
explorado. Estes eixos são sínteses construídas a partir da descrição e análise dos dados em diálogo com o mapa conceitual, que por sua vez são evidenciados na oficina propostas pelo autor e que podem estar contempladas nas discussões sobre cinema e educação.

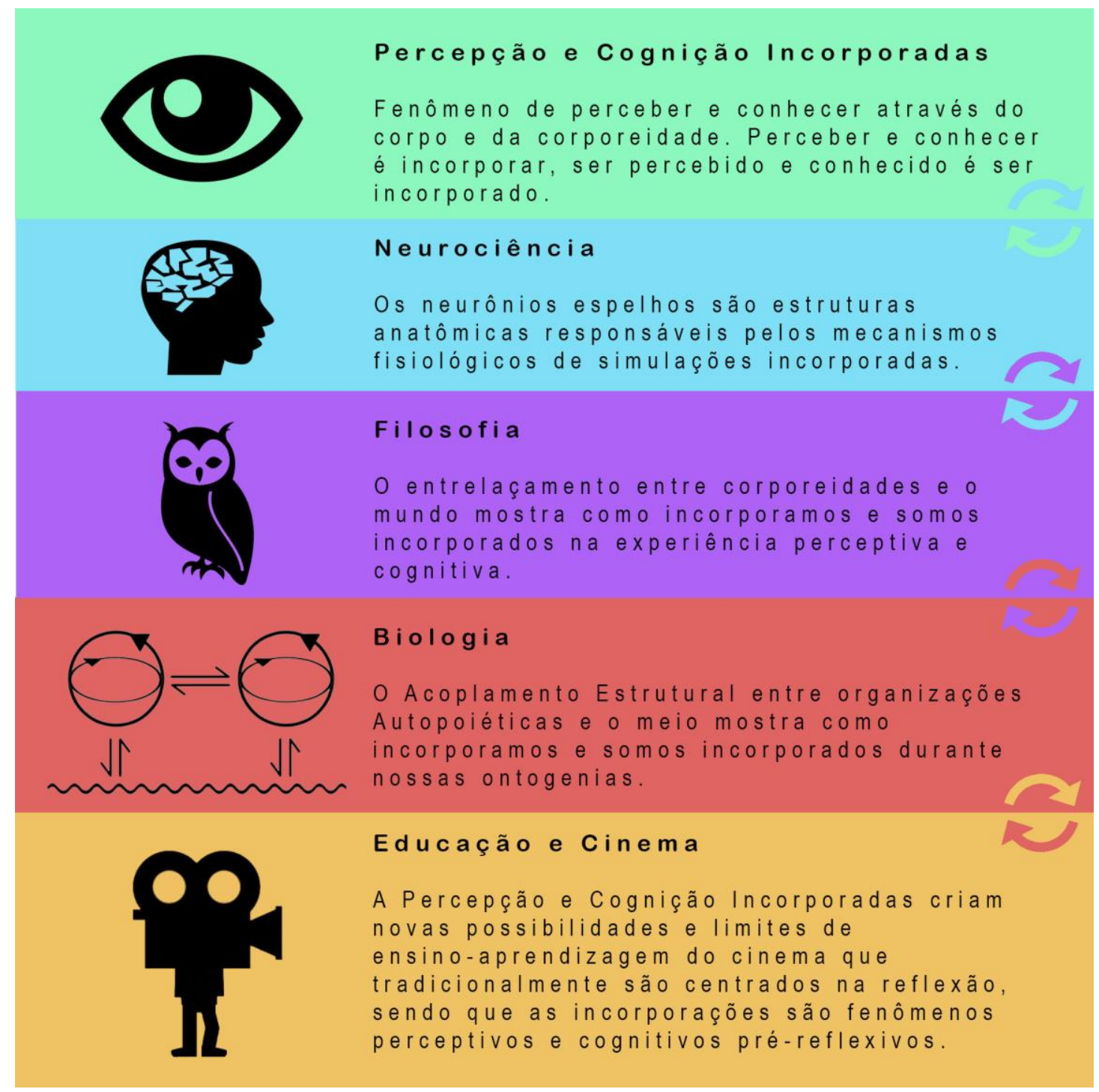

Figura 1: Mapa conceitual (Ferrari, 2015, p.53)

Ferrari (2015) destaca a dimensão criativa e experimental construída na Oficina KINO Incorporando e Sendo Incorporado pelo Cinema - um ambiente digital criado na forma de um website para ampliar as possibilidades de reflexões sobre o ensino-aprendizagem do cinema através da percepção e da cognição incorporadas. A Oficina KINO é composta por cinco módulos: I) Introdução; II) Fotografia Cinematográfica; III) Movimento de Câmera; IV) Montagem Visual; e V) Avaliação. Por sua vez, cada módulo é composto por um conteúdo conceitual introdutório, sugestões de aprofundamento e propostas de atividades relacionadas ao tema da pesquisa. Vale destacar que a referida oficina foi inicialmente elaborada como um piloto para a formação de professores visando contribuir com a 
possível sistematização de uma proposta de ensino-aprendizagem do cinema através das incorporações.

a) Incorporações: a compreensão teórica dos mecanismos e fenômenos da percepção e da cognição incorporadas podem ser apresentadas em diferentes níveis de profundidade. Entretanto, a chave para o desenvolvimento deste tema é a centralidade do corpo e da corporeidade como "sujeitos" da percepção e da cognição. Nesse sentido, o mapa conceitual que construímos pode orientar os caminhos dos professores de educação com e sobre o cinema, contanto que o caminho nunca seja reduzido ao mapa. Através deste mapa conceitual entendemos que a Percepção e Cognição incorporadas pode ser definida sinteticamente como o fenômeno de perceber e conhecer através do corpo e da corporeidade. Perceber e conhecer é incorporar. Ser percebido e conhecido é ser incorporado. O estudo sobre a anatomia e a fisiologia das simulações incorporadas é uma possibilidade mais direta de compreensão das incorporações porque são explicadas pelos próprios experimentos de Rizzolatti et al (1988). Nesse sentido, no campo da Neurociência, os neurônios espelhos são estruturas anatômicas responsáveis pelos mecanismos. Contudo, sem o diálogo com a fenomenologia de Merleau-Ponty, a Biologia do Conhecer de Maturana e Varela (1995), estes experimentos se tornam carentes de possibilidades analíticas e interpretativas mais aprofundadas.

b) Incorporações e cinema: as teorizações cinematográficas, historicamente, foram construídas com base na tradição filosófica e científica dualista que interpreta e explica a percepção e a cognição numa dimensão simbólica como fenômenos e mecanismos exclusivamente mentais, diz Stam (2003). Obviamente há exceções, entre as quais destacamos o trabalho de Merleau-Ponty realizado entre 1940 e 1960.

c) Incorporações, educação e cinema: um desdobramento da centralidade da dimensão simbólica nas teorizações cinematográficas é a permeabilidade do mesmo padrão reflexivo na educação com e sobre o cinema. Como instrumento, o cinema é utilizado pela educação como apoio didático no ensino-aprendizagem de conteúdos disciplinares. Como objeto de estudo, o foco permanece na dimensão simbólica e o ensino-aprendizagem do cinema se aproxima das práticas de alfabetização, no sentido freireano de aprender a ler e escrever o mundo, nesse caso a linguagem do cinema. Nas dimensões instrumentais, críticas e criativas ensinar-aprender a fotografia cinematográfica, o movimento de câmera e a montagem visual nas dimensões simbólicas e de incorporações são vivências semelhantes, porém não são iguais. A partir da centralidade do corpo/corporeidade nos mecanismos e fenômenos de percepção e cognição é possível abrir novas possibilidades e limites para ensinar-aprender cinema, como observamos na Oficina KINO. Nessa experiência, as incorporações também ampliaram as possibilidades reflexivas de análise e interpretação fílmica, de leitura e

Revista Digital do LAV - Santa Maria - vol. 10, n. 2, p. 17 - 38 - mai./ago. 2017 ISSN 1983 - 7348 http://dx.doi.org/10.5902/1983734828785 
escrita.

d) Estrutura didática: ao transferir a reversibilidade de incorporações entre o sentiente e o sensível, segundo Merleau-Ponty (2003), e inspirados na metodologia dos Episódios de Aprendizagem Situada proposta por Rivoltella (2013), criamos a estrutura didática utilizada na Oficina KINO considerando-a como uma importante pista inicial para organizar o ensino-aprendizagem do cinema através das incorporações.

e) Incorporações, visibilidades e sensibilidades: $O$ que foi investigado e refletido nesta pesquisa sobre visibilidade, que para Merleau-Ponty (2003) é o entrelaçamento entre o visível e o vidente, vale para sensibilidade de maneira geral. Inclusive, para refletir e entender as incorporações do áudio no cinema.

f) Espectadores/Operadores de câmera: a reversibilidade de incorporações entre os espectadores e os operadores de câmera é/pode ser apenas uma redução específica das visibilidades cinematográficas. Há especificidades de entrelaçamentos entre os espectadores, atores, diretores de artes, maquinistas, continuístas, enfim, toda equipe cinematográfica. Nos concentramos nas especificidades de entrelaçamento entre espectadores e operadores de câmeras por motivos didáticos que se desdobram das facilidades contemporâneas de ter acesso às câmeras e também por avaliar que estas relações articulam as outras, pois para que uma cena seja filmada é preciso que toda equipe cinematográfica se mobilize para tal. Entretanto, evidenciamos dificuldades técnicas mesmo na proposta simplificada. Inclusive, o uso de selfie apareceu como um elemento de discussão imprevisto que abre outras possibilidades de aprofundamentos para pesquisas posteriores.

g) Incorporações e remix: a recriação de sequências de filmes demonstrou um potencial significativo no ensino-aprendizagem do cinema através das incorporações. Porém, avaliamos que as atividades da Oficina KINO foram reduzidas e que uma proposta didática "ideal"/significativa seria constituída por recriações mais elaboradas, se possível que contemplassem desde a pré-produção até a pós-produção.

h) Limites e Possibilidades da Oficina KINO: o uso da internet foi essencial para a realização da Oficina KINO, sobretudo, porque os participantes da oficina moravam em diferentes cidades. Porém, acreditamos que se houvesse a oportunidade de encontros presenciais e obviamente mais tempo, as contribuições pragmáticas poderiam ser mais qualificadas. A abertura das questões, propostas e atividades também foram um risco assumido, haja vista que se direcionássemos muito as atividades e reflexões poderíamos influenciar nas atividades e reflexões. Também levantamos a hipótese de que alguns enunciados das atividades da oficina talvez não estivessem claros o suficiente e/ou poderiam ter sido elaborados de outras forma, como por exemplo, elaborando a pergunta de outra forma, solicitando algum exemplo ou ainda como um relato em que determinado

Revista Digital do LAV - Santa Maria - vol. 10, n. 2, p. 17 - 38 - mai./ago. 2017 ISSN 1983 - 7348 http://dx.doi.org/10.5902/1983734828785 
aspecto/conceito pudesse ser evidenciado. Por fim, a falta de tempo e o excesso de trabalho dos participantes limitou a qualidade da participação dos mesmos, fato que está presente em suas narrativas, desde o momento da primeira sondagem sobre a possibilidade de participação da Oficina KINO até a finalização do módulo de avaliação.

\section{O desafio das incorporações}

Nesse percurso que partiu da relação entre estética e cinema para qualificar a experiência estética com o cinema, também situamos algumas interpretações das teorias do cinema e suas possibilidades de apropriação educativa. Nesse processo, o destaque a uma abordagem emergente sobre a percepção e cognição incorporada e o cinema se revela um desafio que ainda carece maiores estudos e experiências didáticas.

De um entendimento que enfatiza a experiência estética como estruturalmente relacional e eminentemente corporal, como destaca Diodato (2015), a abordagem da cognição e percepção incorporada na educação com/sobre o cinema sugere que o ensinoaprendizagem do cinema possa ser conduzido através do entendimento de que o corpo é sujeito da percepção e cognição. Ou seja, o corpo não é apenas um meio do cogito cartesiano conforme as tradições científicas e filosóficas ainda hegemônicas pressupõem, sobretudo, no âmbito teórico da educação e do cinema.

Por fim, entre as pistas elencadas a partir de uma oficina de formação na perspectiva apontada, qual seja, a cognição e percepção incorporada, sugerimos que é possível assegurar um espaço à corporeidade ou "vivência/experiência corporal" no âmbito do ensino-aprendizagem do cinema. Com isso, a possibilidade de discutir propostas a respeito de cinema-educação que em alguma medida possam colocar em questão, descondicionar ou mesmo relativizar certas práticas formativas essencialmente "racionalizadas" e por vezes naturalizadas que nos [de]formam. Desse modo, enfatizamos a possibilidade de pensar, ver, sentir o cinema e suas potencialidades para além de considerar que "temos um corpo" e sim que "somos um corpo".

Entre outras possibilidade, a perspectiva apontada também chama a atenção para pensar em formas de recepção cinematográfica visando ressignificar certas compreensões que viam o receptor como "passivo" ou "ativo" na construção de significados, que agora também pode ser problematizado a partir do que "percebe" ou "incorpora", ainda que préreflexivamente. O que nos desafia ainda mais a ponderar o papel do contexto sóciocultural-econômico e das subjetividades nesse processo de percepção, incorporação e também apropriação, sobretudo na perspectiva das mediações.

\section{Referências}

Revista Digital do LAV - Santa Maria - vol. 10, n. 2, p. 17 - 38 - mai./ago. 2017 ISSN 1983 - 7348 http://dx.doi.org/10.5902/1983734828785 
BALAZS, Béla. O homem visível. In XAVIER, I. (org). A experiência do cinema. 3. ed. Rio de Janeiro: Grahal, 1983.

BENJAMIN, W. Obras escolhidas I: Magia e técnica, arte e política: ensaios sobre a literatura e história da cultura. São Paulo: Brasiliense, 1996.

BERGALA, Alain. L'hypothèse cinema: Petit traité de transmission du cinema à l'école et ailleurs. Paris: Cahiers du Cinema, 2002.

CASETTI, Francesco. Teoria del cinema 1945-1990. Milano:Bompiani, 2004.

DALLARI, Marco. La dimensione estética della paideia: fenomenologia, arte, narrativa. Trento: Erickson, 2005.

DELEUZE, Gilles. A imagem-tempo. São Paulo: Brasiliense, 2005.

DESCARTES, Rene. Meditações sobre Filosofia Primeira. Campina: Editora Unicamp, 2004. DIODATO, Roberto . L'invisibile sensibile: itinerari di ontologia estética. Milano: Mimesis Edizioni, 2012.

DIODATO, Roberto. Sobre o sentido da experiência estética. In Revista Tempos e Espaço em Educação, v.8, n.17, set-dez 2015. Disponível em https://seer.ufs.br/index.php/revtee/article/view/4511

EISENSTEIN, Sergei. A Forma do Filme. Rio de Janeiro: Jorge Zahar, 2002.

FANTIN, Monica. Produção cultural para crianças e o cinema na escola. Anais da 26a Reunião Anual da ANPED, Poços de Caldas, 2003.

FANTIN, Monica. Mídia-Educação: conceitos, experiências, diálogos Brasil-Itália. Florianópolis: Cidade Futura, 2006.

FANTIN, Monica. Crianças, Cinema e Educação: além do arco-íris. São Paulo: Annablume, 2011.

FANTIN, Monica. Audiovisual na escola: abordagens e possibilidades. In BARBOSA, M. C. ; SANTOS, M. A. (orgs). Escritos de Alfabetização Audiovisual. Porto Alegre: Libretos, 2014. FANTIN, Monica. Media-education e la dimensione estetica nella pratica pedagogica. Apresentação no Convegno SIREM 2017. Campobasso, 2017.

FERRARI, Rodrigo. Ensinar-aprender cinema: percepção e cognição inroporada. Tese de Doutorado. UFSC/PPGE, 2015.

FRANCO, Marília. Linguagens audiovisuais e cidadania. In Comunicação \& Educação, São Paulo, (91: 32 a 35, maio/ago. 1997.

FREEDBERG, David. El poder de las imagines. Madrid: Ediciones Cátedra, 2011.

FREEDBERG, David; GALLESE, Vittorio. Motion, Emotionand Empathy in Aesthetic Experience. Trends in Cognitive Sciences, 2007.

GALLESE, Vittorio. Embodied Simulation: From neurons to phenomenal experience. Springer. Phenomenology and the Cognitive Sciences, 2005.

Revista Digital do LAV - Santa Maria - vol. 10, n. 2, p. 17 - 38 - mai./ago. 2017 ISSN 1983 - 7348 http://dx.doi.org/10.5902/1983734828785 
GALLESE, Vittorio; GUERRA, Michele. Embodying Movies: Embodied Simulation and Film Studies. Cinema: Journal of Philosophy and the Moving Image, 3: 183-210, 2012.

GALLESE, Vittorio; GUERRA, Michele. Lo schermo empático: cinema e neuroscienze. Milano: Raffaello Cortina Editore, 2015.

LESSIG, Lawrence. Remix: Making Art and Commerce Thrive in the Hybrid Economy. Reino Unido: Bloomsbury Academic, 2008.

MATURANA, Humberto R.; VARELA G., Francisco. A arvore do conhecimento: as bases biologicas do entendimento humano. Campinas: Psy II, 1995.

MERLEAU-PONTY, Maurice. Fenomenologia da percepção. 3. ed. São Paulo: Martins Fontes, 2006.

MERLEAU-PONTY, Maurice. O visível e o invisível. 4. ed. São Paulo: Perspectiva, 2003.

MERLEAU-PONTY, Maurice. The World of Perception. New York: Routledge, 2004.

METZ, Christian. A significação no cinema. São Paulo: Perspectiva, 1972.

MURCH, Walter. Num Piscar de olhos - a edição de filmes sob a ótica de um mestre. Rio de Janeiro: Zahar, 2004.

PINOTTI, Andrea ; SOMAINI, Antonio. Cultura visuale: immagini sguardi media dispositivi. Torino: Piccola Biblioteca Einaudi, 2016.

RAJCHMAN, John. Deleuze. Un mapa. Buenos Aires: Ediciones Nueva Visión, 2007.

RIVOLTELLA, Pier Cesare. L'audiovisivo e la formazione: metodi pre I'analisi. Padova: Cedam, 1998.

RIVOLTELLA, Pier Cesare. Il Cinema Luogo di educazione, tra scuola ed extra-escuola. In. MALAVASI, P.; POLENGHI, S.; RIVOLTELlA, P. C. (orgs) Cinema, Pratiche, Formative, Educazione. Milano: Vita e Pensiero, 2005.

RIVOLTELLA, Pier Cesare. Neurodidattica: Insegnare al cervello che apprende. Milano: Raffaello Cortina Editore, 2012.

RIVOLTELLA, Pier Cesare. Fare didattica con gli EAS: Episodi di Aprendimento Situati. Brescia: La Scuola, 2013.

RIZZOLATTI Giacomo. Functional organization of inferior area 6 in the Macaque monkey. II, 1988.

RIZZOLATTI, Giacomo; FADIGA, Luciano; GALLESE, Vittorio; FOGASSI, Leonardo. Premotor Cortex and the recognition of the actions. Elsiever: Cognitive and Brain Research 3. $131-141,1996$.

RIZZOLATTI, Giacomo; FOGASSI, Leonardo; GALLESE, Vittorio. Neurophysiological mechanisms underlying the understanding and imitation of action. Nature Reviews. Volume 2, Setembro de 2001.

SACKS, Oliver. L'occhio della mente. Milano: Adelphi Edizioni, 2011.

STAM, Robert. Introdução à teoria do cinema. Campinas Papirus, 2003.

Revista Digital do LAV - Santa Maria - vol. 10, n. 2, p. 17 - 38 - mai./ago. 2017 ISSN 1983 - 7348 http://dx.doi.org/10.5902/1983734828785 
VARELA, Francisco; THOMPSON, Evan; ROSH, Eleanor. The embodied mind: cognitive Science and human experience. MIT Press, 1993.

XAVIER, Ismail (org). A experiência do cinema. 3. ed. Rio de Janeiro: Grahal, 1983.

XAVIER, Ismail. Um Cinema que "Educa" é um Cinema que (nos) faz Pensar. Educação e Realidade. v. 33, n. 1, 2008.

i Doutor em Educação pelo PPGE/UFSC, realiza pós-doutorado em Educaçao Física no PPGEF/UFSC. Licenciado e Mestre em Educação Física pela mesma universidade, é pesquisador do Observatório da Mídia Esportiva, LABOMÍDIA/UFSC e do Núcleo Infância Comunicação Cultura e Arte, NICA, UFSC/CNPq . Email rd.ferrari@gmail.com

ii Doutora em Educação com Pós-Doutorado em Estética, Professora Associada do Departamento de Metodologia do Ensino e do Programa de Pós-Graduação em Educação, do Centro de Ciências da Educação da Universidade Federal de Santa Catarina. Líder do Grupo de Pesquisa Núcleo Infância Comunicação Cultura de Arte, NICA/UFSC/CNPq. Email monica.fantin@ufsc.br

Enviado em: 29 de junho de 2017.

Aprovado em: 13 de julho de 2017. 